\title{
Cardiovascular risk factors in first-degree relatives of patients with hypertension*
}

\author{
Patricia Landázuri, PhD¹, Nelsy Loango, MSc ${ }^{2}$, Martha Lucía Gallego, Spc ${ }^{1}$
}

\section{SUMMARY}

Objective: To evaluate the prevalence of cardiovascular risk factors (CRF) and absolute risk (AR) among first-degree consanguinity relatives of Colombian patients with hypertension.

Methods: The study comprised 227 relatives (siblings and children of both sexes, between 12 and 40 years of age) and 204 hypertensive patients 34-84 years old from Quindío, Colombia. Lipid profile, glycemia, smoking, body mass index, and blood pressure were analyzed, and the AR of cardiovascular disease (CVD) to 10 years was estimated. Relatives were divided into two groups: GF1 relatives $\leq 18$ years, GF2 relatives $>18$ years.

Results: three or more CRF were found in the three groups. The prevalence for smoking was $20.1 \%, 9.1 \%$, and $15.9 \%$ in patients, GF1, and GF2, respectively. Hypercholesterolemia was $42.2 \%, 15.2 \%$, and $18.6 \%$ in patients, GF1, and GF2, respectively. The prevalence of low HDL-c levels was 50.5\%, 44.9\%, and 63.6\% in relatives, GF1, and GF2, respectively. Obesity was present alone in patients, (32.4\%) and GF2 (10.8\%). The AR was 19.6 and 6.4 in male and female patients, respectively; 0.31 and 0 in GF1 females and males, respectively, and in GF2 it was 1.5 and 0.15 in males and females, respectively.

Conclusions: Patients and relatives had more than three CRFs. HDL-c was low in all three groups. The AR was high in the young relatives. Programs are needed for weight, smoking, sedentary and dyslipidemia control to prevent or delay the development of CVD in relatives.

Keysword: Cardiovascular disease; Cardiovascular risk factors; Absolute risk; Hypertension; Relatives; Smoking; Hypercholesterolemia.

Colomb Med. 2011; 42: 17-25

Factores de riesgo cardiovascular en consanguíneos de pacientes hipertensos

\section{RESUMEN}

Objetivo: Evaluar la prevalencia de Factores de Riesgo Cardiovascular (FRC), y Riesgo Absoluto (RA) en familiares consanguíneos de pacientes colombianos hipertensos.

Métodos: Se estudiaron 227 familiares (hermanos e hijos de ambos sexos, entre 12-40 años de edad), y 204 pacientes hipertensos (34-84 años) del Quindío, Colombia. Los familiares se dividieron en dos: grupo de familiares $\leq 18$ años (GF1) y grupo de familiares $>18$ años (GF2). Se analizaron perfil lipídico, glicemia, tabaquismo e índice de masa corporal y se calculó el RA de sufrir enfermedad cardiovascular (ECV) a 10 años.

Resultados: Se encontraron tres o más FRC en los tres grupos (pacientes, GF1 y GF2). La prevalencia de tabaquismo fue $20.1 \% 9.1 \%$ y $15.9 \%$ en pacientes, GF1 y GF2 respectivamente. La hipercolesterolemia fue $42.2 \% 15.2 \%$ y $18.6 \%$ en pacientes, GF1 y GF2 respectivamente. La prevalencia de niveles bajos de c-HDL fue 50.5\%, 44.9\% y $63.6 \%$ en familiares, GF1 y GF2, respectivamente. Mientras que la obesidad sólo estuvo presente en los pacientes (32.4\%) y en el grupo GF2 (10.8\%). El RA fue de 19.6 y 6.4 en los pacientes de género masculino y femenino, respectivamente; de 0.31 y 0 en el GF1

* This work was supported by grants 1944, from Fundaciones Banco de la República and 290 from Universidad del Quindío.

1. Professor, Medicine Program, Faculty of Health, Universidad del Quindío, Armenia, Colombia. e-mail: plandazu@uniquindio.edu.co mgallego@uniquindio.edu.co

2. Assistant Professor, Biology Program, Faculty of Basic Sciences and Technologies, Universidad del Quindío, Armenia, Colombia. e-mail: neloango@uniquindio.edu.co

Received for publication May 24, $2010 \quad$ Accepted for publication September 14, 2010 
femenino y masculino, respectivamente; de 1.5 y 0.15 en el GF2 masculino y femenino, respectivamente.

Conclusiones: Pacientes y familiares tenían más de tres FRC. El c-HDL fue bajo en los tres grupos. El RA fue alto en los familiares jóvenes. Se necesitan programas para el control de peso, tabaquismo, sedentarismo y dislipidemias para prevenir o retrasar el desarrollo de ECV en los familiares.

Palabras clave: Enfermedades cardiovasculares; Factores de riesgo cardiovascular; Riesgo absoluto; Hipertensión; Parientes; Tabaquismo; Hipercolesterolemia.

\section{Colomb Med. 2011; 42: 17-25}

Cardiovascular disease (CVD) causes millions of deaths per year around the world ${ }^{1}$. In Colombia, after violent deaths, CVD occupies the second place, within the first five causes of mortality in the nation's general population ${ }^{2}$. Hypertension is a risk factor for CVD, in Colombia close to $24.7 \%$ of the adult population suffers from hypertension ${ }^{3}$, which contributes to the high prevalence of CVD in the country.

Evidence from epidemiological studies, clinical correlations, and genetic studies among others indicate that high levels of cholesterol, triglycerides, low-density lipoprotein cholesterol (LDL-c), lipoprotein A, apolipoprotein B, as well as low levels of high-density lipoprotein cholesterol (HDL-c), hypertension, obesity, tobacco smoking, and sedentary life style, among others, are cardiovascular risk factors (CRF). Identifying and managing CRFs in patients in populations has permitted reducing deaths due to CVD in the last 25 years ${ }^{4}$.

Several studies have been done in Colombia on CRFs is specific population groups, like individuals with a first coronary event ${ }^{5}$, as well as healthy children and adults from different regions of the country ${ }^{6-8}$, but none-according to available literature-includes consanguineous relatives of individuals with hypertension who can have one or more CRF. For this reason, a family focus is most appropriate in identifying and preventing the CRFs, given that epidemiological studies have manifested that around $30 \%$ to $50 \%$ of the interindividual blood pressure variation in the population is genetically determined ${ }^{3}$.

Hence, the objective of this work was the analysis of the CRFs present in young consanguineous relatives of hypertensive patients to contribute to knowledge on the disease; thereby, improving the quality of life of hypertensive patients and their families and helping healthcare authorities make decisions on prevention policies in families.

\section{MATERIALS AND METHODS}

This was a cross-sectional, descriptive study conducted from 2007-2009, with a representative sample of the hypertensive population from health centers, Healthcare Promotion Companies, and community centers with hypertension control programs in the Department of Quindío in Colombia, with 95\% reliability and 5\% sampling error.

Study subjects. The study was conducted with hypertensive Colombian men and women between 34 and 84 years of age, and with their young (between 12 and 40 years of age) Colombian relatives, in first degree of consanguinity ( siblings and offspring), from different entities like healthcare centers, Healthcare Promotion Companies, and community centers with hypertension control programs in the Department of Quindío in Colombia (we did not explore patient birth place nor did we include ethnicity markers in the study). All the healthcare centers in the department were considered. The selection was established by conglomerates of healthcare centers and it was conducted via a simple random sampling. The selection of the participating hypertensive individuals was done via a systematic random sampling on the registration lists. The patients were contacted by telephone or at their healthcare centers. The study excluded relatives diagnosed with chronic pulmonary hypertension, previous thyroid disorders, prior type-I and type-II diabetes, as well as pregnant women, and those voluntarily leaving the study. Basic demographic information was obtained through a survey held at the site where the samples were taken. This work was approved by the Bioethics institutional committee in Universidad del Quindío. All the participants signed an informed consent form; in all cases, there was strict compliance with the ethical principles contained in the 1964 Helsinki declaration and its modifications until 2008 and with Resolution 8430 of 1993 from the Colombian Ministry of Social Protection. The total simple was of 431 individuals among hypertensive patients and relatives.

Definition of variables. The study variables were: 
Blood pressure, body mass index (BMI), tobacco smoking, blood lipids, glycemia, age, and gender; hypertension was defined as systolic pressure $>140$ and/or diastolic pressure $>90 \mathrm{mmHg}$, taken from a seated individual ${ }^{9}$; overweight was indicated by BMI between 25 and $29.9 \mathrm{~kg} / \mathrm{m}^{2}$, and obesity was established by $\mathrm{BMI} \geq 30 \mathrm{~kg} / \mathrm{m}^{2}$. Tobacco smoking was taken as the consumption of at least one cigarette within the last month $^{10}$; sedentary life style as the lack of regular physical activity ( $>30$ minutes, $\geq 3$ days/week $)^{11}$, the type of exercise was not considered nor the intensity of such, only the duration (time) and frequency (days/ week). Although the survey inquired on the type of diet [foods ingested within the last two days (breakfast, lunch, and dinner)], this variable was not controlled. For lipid profile values, we considered abnormal total cholesterol (TC) $>200 \mathrm{mg} / \mathrm{dl}$, HDL-c $<40 \mathrm{mg} / \mathrm{dl}$ in men and $<50 \mathrm{mg} / \mathrm{dl}$ in women, triglycerides $(\mathrm{TAG})>150$ $\mathrm{mg} / \mathrm{dl}$, and LDL-c $>130 \mathrm{mg} / \mathrm{dl}$ after fasting for $12 \mathrm{~h}$; according to the National Cholesterol Education Program (NCEP) $)^{12}$, hyperglycemia was defined as fasting glycemia $\geq 125 \mathrm{mg} / \mathrm{dl}^{13}$.

Procedures. Blood samples were obtained at the respective healthcare centers, after $12 \mathrm{~h}$ of fasting via venipuncture in dry tube, the serum was obtained via centrifuge at $2500 \mathrm{~g}$ for 15 minutes at $4^{\circ} \mathrm{C}$, separated in micro-tubes and stored at $-20^{\circ} \mathrm{C}$ until used. Body weight registered in kilograms with one decimal place was measured with an electronic scale $(0.1-\mathrm{kg}$ precision). Height was measured with a stadiometer (sensitivity: 1 $\mathrm{mm}$ ) and it was registered in meters with two decimal places. Each measurement was taken by previously standardized personnel and registered twice. BMI in $\mathrm{kg} / \mathrm{m}^{2}$ was calculated with height and weight. Total cholesterol, TGA, and HDL-c were measured via commercial enzymatic methods. For those with triglycerides $<400 \mathrm{mg} / \mathrm{dl}$, LDL-c was calculated with the Friedewald equation ${ }^{14}$ and VLDL $=\mathrm{TGA} / 5$.

Evaluation and stratification of the cardiovascular risk. Absolute risk (AR) was defined as the probability of developing coronary or cardiovascular disease during a given period of time ${ }^{15,16}$. In this study, AR was measured at 10 years and it was calculated after knowing the deduced score of the risk factors; to find the score, six variables were considered, modifying the score according to gender, age (years), TC (mg/dl), HDL-c (mg/dl), glycemia (>126 mg/dl, yes, no), systolic pressure $(>120 \mathrm{mmHg}$ ), and smoker (yes, no), using modified and adapted tables from Grundy et al. ${ }^{15}$ and Wilson et al. ${ }^{16}$

Statistics. The Kolmogorov Smirnov test was applied to determine if the variables had a normal distribution. Confidence intervals at $95 \%$ were calculated for differences of proportions and a Chi-square distribution was done to see the significance level. This was established at $p<0.05$. AR was calculated based on the sum method of risk factors ${ }^{15,16}$. Thereafter, we classified individuals into slight risk (below the AR average for the population), moderate risk (three times above the AR average for the population), and high risk (four times above the AR average for the population). As the average AR, we took AR of the study subject population. The data are presented as the mean \pm the standard error. The means of the anthropometric data and the metabolic characteristics were compared among groups using the one-way variance analysis (ANOVA). The statistical analysis was done with the SPSS program version 16.0.

\section{RESULTS}

Baseline characteristics of the population. The study was conducted with 431 subjects; 204 hypertensive individuals and 227 relatives in first degree of consanguinity (offspring and siblings between 12 and 40 years of age). Table 1 shows the baseline characteristics of the population. Of the hypertensive individuals, $85.7 \%$ were women and $14.2 \%$ were men. Because of the broad range of ages of the relatives, these were distributed into two groups, one with women and men $\leq 18$ years of age (GF1) and another group with women and men $>18$ years of age (GF2). GF1 represented $14.5 \%$ of the relatives, while GF2 represented $85.5 \%$. The female population had the highest presence in the three groups studied, representing $70.5 \%$.

Data from Table 1 show that the hypertensive patients had higher systolic and diastolic pressure than those of their relatives, even though many of the patients were medicated (data not shown); hypertensivemen presented higher values of both types of pressure than women in the group, with significant differences for diastolic pressure. In GF2, men had higher systolic and diastolic pressure tan women with significant differences; however, both pressure figures were within normal ranges. With respect to BMI, the results indicate that on 
Table 1

Baseline characteristics of the study participants

\begin{tabular}{|c|c|c|c|c|c|c|}
\hline \multirow[t]{2}{*}{ Variable } & \multicolumn{2}{|c|}{ Patients ( $n=204$ ) } & \multicolumn{2}{|c|}{ GF1 $(n=33)$} & \multicolumn{2}{|c|}{ GF2 (n=194) } \\
\hline & $F(n=175)$ & $M(n=29)$ & $F(n=17)$ & $M(n=16)$ & $F(n=112)$ & $M(n=82)$ \\
\hline Age (years) & $58.9 \pm 0.7$ & $62.1 \pm 2.1$ & $15.7 \pm 0.5$ & $15.3 \pm 0.6$ & $33.0 \pm 0.6$ & $30.7 \pm 0.8^{*}$ \\
\hline $\mathrm{BMI} \mathrm{Kg/ \textrm {m } ^ { 2 }}$ & $28.3 \pm 0.4$ & $28.1 \pm 0.6$ & $20.5 \pm 0.6$ & $19.7 \pm 0.8$ & $24.6 \pm 0.43$ & $24.4 \pm 0.4$ \\
\hline $\mathrm{SP} \mathrm{mmHg}$ & $129.6 \pm 1$ & $134.3 \pm 2,9$ & $95.8 \pm 2.4$ & $100.3 \pm 2.7$ & $105.7 \pm 1.1$ & $113.5 \pm 1.3^{*}$ \\
\hline $\mathrm{DP} \mathrm{mmHg}$ & $71.2 \pm 1.1$ & $81.1 \pm 2.1^{*}$ & $53.1 \pm 1.8$ & $53.6 \pm 2.9$ & $59.5 \pm 1.1$ & $67.6 \pm 1.3$ \\
\hline
\end{tabular}

GF1=relatives $\leq 18$ years $G F 2=$ relative $>18$ years $F=$ female $M=$ male $B M I=$ body mass index $S P=$ systolic pressure $\mathrm{DP}=$ diastolic pressure ${ }^{*}$ significant differences due to gender among the age groups, $p<0.05$

Table 2

Lipid profile and glycemia for study participants

\begin{tabular}{|c|c|c|c|c|c|c|}
\hline \multirow[t]{2}{*}{ Variable } & \multicolumn{2}{|c|}{ Patients $(n=204)$} & \multicolumn{2}{|c|}{ GF1 (n=33) } & \multicolumn{2}{|c|}{ GF2 (n=194) } \\
\hline & $F(n=175)$ & $M(n=29)$ & $\overline{F(n=17)}$ & $M(n=16)$ & $F(n=112)$ & $M(n=82)$ \\
\hline TC (mg/dl ) & $200.3 \pm 3.9$ & $179.1 \pm 8.3^{*}$ & $157.4 \pm 7.8$ & $160.4 \pm 10.8$ & $170.9 \pm 3.6$ & $175.2 \pm 5.0$ \\
\hline LDL-c (mg/dl ) & $127.2 \pm 3.4$ & $104.8 \pm 7.7^{*}$ & $95.9 \pm 7.1$ & $93.5 \pm 8.6$ & $106.0 \pm 3.2$ & $101.9 \pm 4.4$ \\
\hline VLDL-c (mg/dl ) & $33.2 \pm 1.1$ & $39.0 \pm 2.7^{*}$ & $21.8 \pm 2.1$ & $30.1 \pm 8.8$ & $22.2 \pm 1.0$ & $34.8 \pm 3.3^{*}$ \\
\hline TGA (mg/dl ) & $169.9 \pm 6.4$ & $197.9 \pm 14.7^{*}$ & $109.1 \pm 10.3$ & $106.9 \pm 13.5$ & $111.3 \pm 5.1$ & $182.2 \pm 19.8^{*}$ \\
\hline HDL-c (mg/dl ) & $41.5 \pm 0.9$ & $35.3 \pm 1.6^{*}$ & $39.7 \pm 2.1$ & $42.4 \pm 2.8$ & $42.6 \pm 0.8$ & $39.0 \pm 1.1^{*}$ \\
\hline Glycemia (mg/dl) & $86.1 \pm 1.7$ & $84.8 \pm 3.5$ & $75.1 \pm 1.7$ & $79.7 \pm 2.1^{*}$ & $73.2 \pm 0.9$ & $79.5 \pm 2.0^{*}$ \\
\hline
\end{tabular}

GF1=relatives $\leq 18$ years $G F 2=$ relatives $>18$ years $F=$ female $M=$ male * significant differences due to gender among the age groups, $p<0.05$

average there is slight overweight condition in patients (men and women), but not with their relatives.

Lipid profile and glycemia.Table 2 summarizes results found in these variables. Lipid profile presented higher levels of TC and LDL-c in the female population of patients, with significant differences with respect to male patients; nevertheless, the means for both parameters were within the normal limits in all the population groups. VLDL-c was always higher in men than in women with significant differences for the patient group and for the GF2 group. Triglycerides were high in men from the patient group and from the GF2 group, differences were significant with respect to women in each group. In both groups of individuals (male patients and GF2 males), triglycerides were above the normal range. HDL-c levels in all groups were below normal parameters. Glycemia was also within the normal parameters in all the groups, showing significant differences only between gender in groups GF1 and GF2.

Prevalence of cardiovascular risk factors different from hypertension. Table 3 shows that the prevalence for smoking was presented in the following order: $20.1 \%, 9.1 \%$, and $15.9 \%$ for patients, GF1, and GF2, respectively, without significant differences among groups. Hypercholesterolemia (HC) (cholesterol $>200$ $\mathrm{mg} / \mathrm{dl}$ ) was at $42.2 \%, 15.2 \%$, and $18.6 \%$ for patients, GF1, and GF2, respectively, with significant differences between patients and GF $1(p<0.001)$ and between GF1 and GF2 $(p<0.006)$. The variance analysis for the three groups revealed significant differences between groups $(<0.001)$. Sedentary life style was notorious in all the groups, $31.7 \%$ of patients engaged in exercises, while relatives were engaged in exercise activity by $45.5 \%$ and $25.4 \%$ for groups GF1 and GF2, respectively. 
Table 3

Prevalence of risk factors in the study group

\begin{tabular}{lccc}
\hline \multicolumn{1}{c}{ Variable $\%$} & Patients $(\mathbf{n = 2 0 4 )}$ & GF1 $(\mathbf{n = 3 3 )}$ & GF2 (n=194) \\
\hline Smoking & 20.1 & 9.1 & 15.9 \\
Hypercholesterolemia & 52.2 & $15.2^{1}$ & $18.6^{2}$ \\
HDL-C & 50.5 & 44.9 & 63.6 \\
Obesity & 32.4 & 0.0 & 20.8 \\
Sedentary life style & 68.3 & 54.5 & $47.6^{3}$ \\
\hline
\end{tabular}

GF1=relatives $\leq 18$ years GF2=relatives $>18$ years 1 . Significant differences between patients and GF1.

2. Significant differences between GF1 and GF2. 3. Significant differences among the groups

Table 4

Average value per risk factor and 10 -year risk percentage in each study group

\begin{tabular}{|c|c|c|c|c|c|c|}
\hline \multirow[t]{2}{*}{ Variable } & \multicolumn{2}{|c|}{ Patients ( $n=204)$} & \multicolumn{2}{|c|}{ GF1 $(n=33)$} & \multicolumn{2}{|c|}{ GF2 (n=194) } \\
\hline & $F(n=175)$ & $M(n=29)$ & $F(n=17)$ & $M(n=16)$ & $F(n=112)$ & $M(n=82)$ \\
\hline Age & 8.5 & 8.9 & -7 & -9 & -4.7 & -6.5 \\
\hline SP & 3.3 & 1.6 & 0 & 0 & 0.1 & 0.1 \\
\hline Smoker & 0.63 & 0.9 & 0.5 & 1 & 1 & 1.6 \\
\hline $\mathrm{TC}$ & 2.3 & 1.5 & 3.1 & 2.5 & 2.9 & 3.3 \\
\hline HDL-C & 1.2 & 1.6 & 1.5 & 1.2 & 1.1 & 1.3 \\
\hline Glycemia & 0.18 & 0.07 & 0 & 0 & 0 & 0 \\
\hline Total points & 16.11 & 14.6 & -1.9 & -4.3 & 0.4 & -0.2 \\
\hline AR $\%$ at 10 years & 6.4 & 19.6 & 0 & 0.31 & 0.15 & 1.5 \\
\hline
\end{tabular}

$A R=$ absolute risk. GF1=relatives $\leq 18$ years. GF2=relatives $>18$ years. $F=$ female, $M=$ male. No significant differences were found.

Regarding low levels of HDL-c, the distribution was $50.5 \%, 44.9 \%$, and $63.6 \%$ for patients, GF1, and GF2, respectively. Significant differences were only found between patients and GF1 $(\mathrm{p}<0.001)$ and between groups GF1 and GF2 $(\mathrm{p}<0.01)$. In the obesity risk factor, there were no significant differences among the groups, but Graphic 1 shows a greater percentage of obesity in the patient group.

Average score per risk factor and percentage of risk at 10 years. Table 4 shows the average score for each factor in each of the groups and the percentage of AR at 10 years in each study group. As expected, male patients have greater AR (19.6\%) of suffering a coronary event than female patients or the groups of relatives. Men in GF2 have a higher percentage of risk compared to men in GF1 and to women in both groups.

Also, data in Table 3 indicate that except for hypertension and age in patients, the CRFs contributing most to AR -in patients and relatives- were high TC and low levels of HDL-c. In the male CF2 group, smoking habit also contributed to the risk. Glycemia contributed to the risk only in the patient group. Regarding AR at 10 years, it was almost three times higher for male patients than for female patients.

Classification of cardiovascular risk factor by levels. Graphic 1 shows the classification of the individuals of the study in three risk levels: limit, medium, and high; revealing greater risk for males in the patient group and lower risk for females in the GF2 group. 


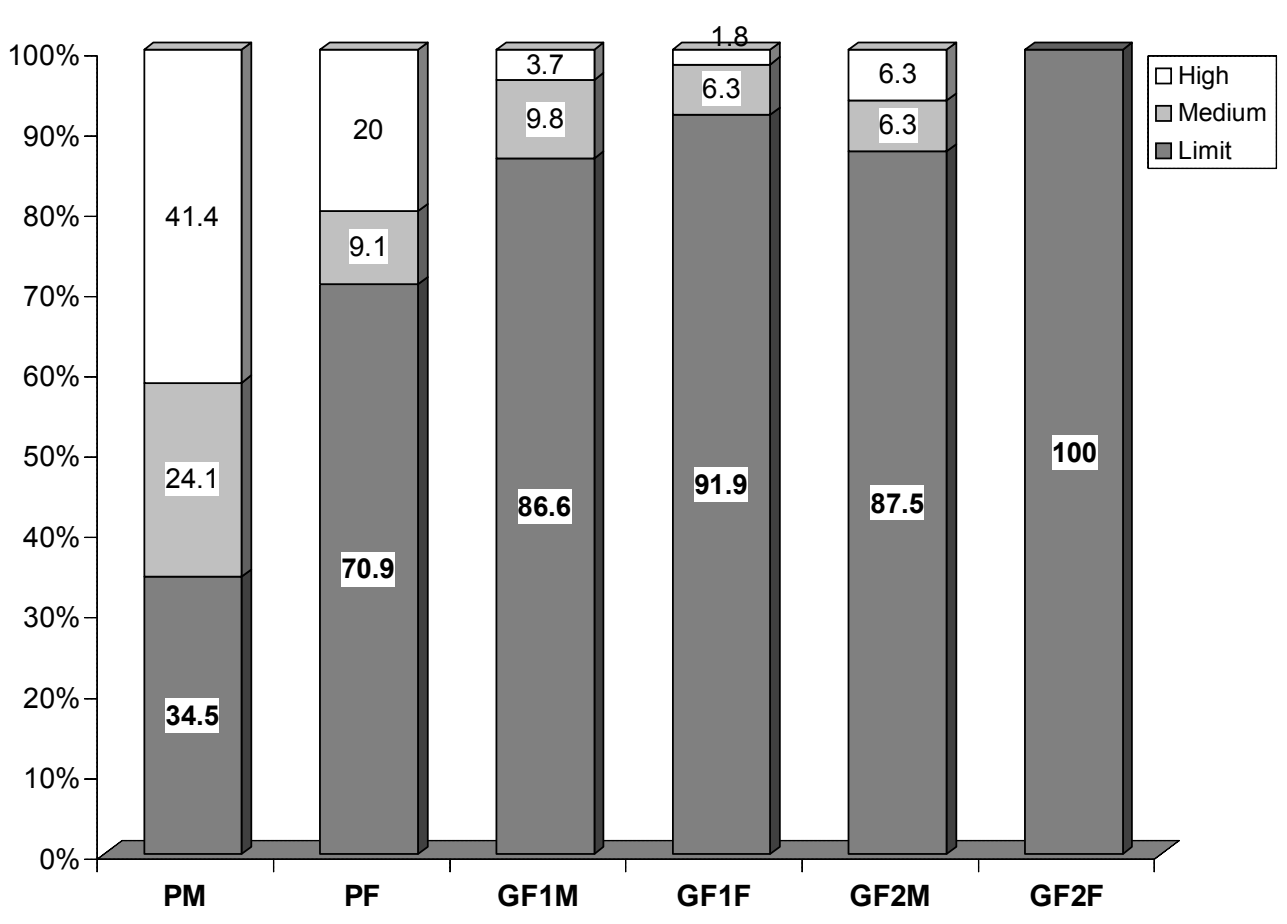

Graphic 1. Classification of absolute risk in the study population

$\mathrm{MP}=$ male patient, $\mathrm{FP}=$ female patient. $\mathrm{GF} 1 \mathrm{M}=$ male relatives $\leq 18$ years. GF2M $=$ male relatives $>18$ years. GF1F $=$ female relatives $\leq 18$ years. $\mathrm{GF} 2 \mathrm{~F}=$ female relatives $>18$ years

\section{DISCUSSION}

Herein, we describe the prevalence of CRFs and the absolute risk of suffering cardiovascular disease at 10 years in hypertensive patients and their relatives in first degree of consanguinity, given that several studies show that the hereditary part for hypertension varies between $35 \%$ and $65 \% .{ }^{10}$. This agreement of hypertension in families has been attributed to several reasons, among them sharing the same exposure to environmental factors and common genetic components.

Results indicate that the sampling of this study was constituted in all the groups, mainly by women, which is habitual in this type of work, in part, due to the low number of men attending controls for hypertension or for chronic disease, and in part, because of the labor difficulties of men or because they worry less about their health, as has been demonstrated by several studies on $\mathrm{CRF}^{17,18}$. In this regard, Friedman et al., ${ }^{18}$ describe that there was better correlation between findings of hypertension in the mother-offspring pair than in the father-offspring pair. The authors attribute this to the relatives; and although the sample was not representative when divided into groups, even in the youngest individuals hypercholesterolemia was above that described for young healthy populations from other regions of the country ${ }^{7}$.

Obesity is a growing problem in Western nations, including Colombia. It affects adult and young populations. In our study population we found obesity in nearly $32 \%$ of the hypertensive patients and their relatives $>18$ years of age, there is a considerable prevalence $(10.8 \%)$, although it is lower than that found in another study ${ }^{17}$. This finding points to the risk these young adults have of suffering CVD, given that some authors state that being overweight during childhood, adolescence, or youth increases the risk of suffering CVD, or other chronic diseases like diabetes, certain types of cancer, and psychiatric problems ${ }^{19}$. A sedentary life style is related to obesity, said life style is considered an important risk factor for CVD in the general population. Research shows that physical activity provides metabolic and cardiovascular benefits, although the amount, intensity, and frequency are still under 
discussion. In this regard, in the survey done with the study population, a high percentage of them referred to practicing physical activity (walking) once and sometimes twice per week (data not shown), which placed them as sedentary according to study parameters; this explains the high percentage of sedentary life styles found in the study, and suggests that for the population the relationship is not clear between intensity and frequency of exercise with the benefits in reducing cardiovascular risk.

For the tobacco smoking factor, we observed that it was not only present in the patients, but that it was present in a high percentage of the young and adult relatives; although for the young relatives we found lower rates of tobacco smoking than described in other Colombian adolescents ${ }^{7,20}$ it is important to note that smoking figures weighed considerably when estimating absolute risk of suffering CVD in this group.

HDL-c levels in serum were very low for all the groups including the youngest, compared to international standards ${ }^{12}$, this finding is repetitive for diverse population groups studied in the department of Quindío $^{5,6}$ and in Colombia ${ }^{7,8}$, and possibly as shown by the AR calculation in this work, contributes significantly to cardiovascular disease.

The presence of three or more CRFs in relatives of hypertensive patients may possibly be explained based on the premise that parents, children, and siblings share, in addition to their genetic susceptibility, the same family and social realm (diet, habits, income, and education, among others). Similar findings already shown in studies like that of Johnson et al. ${ }^{21}$ which describes that a small cohort of children with high blood pressure have parents with a higher-than-expected prevalence for hypertension, hypercholesterolemia, and for being overweight; similar to that reported by Reis et al., ${ }^{22}$ who found a correlation between the mean BMI, waist circumference, blood pressure, and blood levels of TAG, TC, and HDL-c of parents and offspring; additionally, these authors also found a strong association for many of the CRFs between parents and their children. Regarding the short-term (10 years) estimation of $A R$, it is known that this is potentially useful for identifying individuals who need an aggressive reduction of the risk factor; in this work for example, we show that hypertensive patients -in spite of being medicated (data not shown)- continue displaying slightly high values of pressure, hypercholesterolemia, very low levels of HDL-c, and overweight condition; these findings in the patients could have several interpretations: that the treatment for hypertension and other CRFs is not suitable, that monitoring of such is deficient, that patients are careless with their medications; that there is insufficient education on their own health, self care and healthy life styles, or a mixture of these.

Although for some clinicians, in their daily practice, pressure levels of 130/80 $\mathrm{mmHg}$ are taken as slightly normal and our groups of patients were very close (women 129/71 mmHg) or slightly above (men 134/81 $\mathrm{mmHg}$ ), this -together with other risk factors as those found in patients from the study-predisposes them to $\mathrm{CVD}^{23}$, particularly if they are not cared for during long periods; this is indicated by the high figures of absolute risk found in men (19.6\%) and in women (6.4\%); values higher than those described by Jaramillo et al. ${ }^{9}$ for a Colombian adult population; the difference between the two populations is probably due to the presence of a risk factor (hypertension) as a selection criterion of the population from the current study.

The AR determination revealed that it is not only important in monitoring patients, but that its calculation is quite important for their young relatives; because albeit in the short-term AR does not appear significant, in the long term, AR could be unacceptably high due to its progressive increase with age ${ }^{23}$. Also, the classification of risk into three levels: limit, moderate, and high revealed the same tendency as AR, although most of the relatives from both groups were within the range limit, many of them already presented moderate and even high risk, particularly male relatives.

Our study had important limitations like: the size of the sample (in spite of it being representative of the hypertensive population from the healthcare centers), the group of relatives includes two types offspring and/ or siblings, their age ranges (in adults decisions taken on life style is less influenced by their hypertensive relative), the impossibility for controlling their diet (which could generate bias), not including alcohol consumption, and not determining ethnic markers. These limitations did not facilitate the analysis of relationship or association among factors; however, it is clear that the data show a high prevalence of some CRFs in the relatives of these patients. 
Hence, early detection of risk in young individuals like those in our study shows the need for early and prolonged intervention of the CRFs, even in those with values of moderate or no risk as revealed by several studies relating CRF between parents and their children $^{24}$.

\section{CONCLUSIONS}

Data from the current study indicate that an important percentage of patients exhibit several CRFs in addition to hypertension. The CRFs found in hypertensive patients are also present in their relatives, inclusively in their younger relatives. The most frequent were hypercholesterolemia, tobacco smoking, sedentary life style, and low levels of HDL-c. The population studied, subject to high and medium risk of suffering cardiovascular disease at 10 years was over $50 \%$.

These results should motivate health authorities to implement intervention programs, through medical or prevention services, in healthcare units for hypertensive individuals and in entities caring for their relatives. These programs should tend to diminish the main cardiovascular risk factors, especially by diminishing overweight conditions, maintaining tension figures within adequate ranges, increasing values of HDL-c, as well as combating cigarette smoking.

Conflict of interest. None of the authors has conflicts of interest related to this study.

\section{REFERENCES}

1. World Health Organization. The World Health report 2002: reducing risks, promoting healthy life. Geneva: WHO; 2002. p. $1-230$.

2. Ministerio de Salud, Instituto Nacional de Salud, Organización Panamericana de Salud. Situación de salud en Colombia. Indicadores básicos. Bogotá, DC: Ministerio de Salud, Instituto Nacional de Salud, Organización Panamericana de Salud; 2002.

3. Aristizábal D, García E, McEwen J, Caulfield M, Méndez J, Medina E, et al. Bases genéticas de la hipertensión arterial esencial en Colombia: avances en nueve años de estudio. Rev Colomb Cardiol. 2006; 12: 409-30.

4. Sistino JJ. Epidemiology of cardiovascular disease in the last decade: treatment options and implications for perfusion in the 21st century. Perfusion. 2003; 18: 73-7.

5. García G, Restrepo B, Trejos J, Landázuri, P. Homocysteine, folates and B12 vitamin in Colombian patients with coronary disease. Arq Bras Cardiol. 2007; 89: 71-6.
6. Landázuri P, Loango N, Gallego ML, Restrepo B. Diferencias de sexo, edad y lípidos plasmáticos asociadas al polimorfismo de la apolipoproteína E en un grupo de escolares de Quindío, Colombia. Biomedica. 2009: 29: 382-91.

7. Uscategui-Peñuela RM, Álvares-Uribe MC, Leguado-Salinas I, Soler-Terranova W, Martínez-Maluendas L. Arias-Arteaga $\mathrm{R}$, et al. Factores de riesgo cardiovascular en niños de 6 a 18 años de Medellín, Colombia. An Pediat (Barc) 2004; 58: 411-7.

8. Jaramillo NI, Torres-Galvis Y, Echevarría E, Llamas A, Jiménez LP, Montoya, $K$, et al. Estudio sobre factores de riesgo cardiovasculares en una población de influencia de la Clínica Las Américas. Rev CES Med. 2004; 18: 9-18.

9. Chobaniam AV, Bakris GL, Black HR, Cushman WC, Green LA, Izzo JL, et al., and the National High Blood Pressure Education Program Coordinating Committee. The Seventh Report of the Joint National Committee on Prevention, Detection, Evaluation, and Treatment of High Blood Pressure. The JNC 7 Report. JAMA. 2003; 289: 2560-72.

10. Chow CK, Jolly S, Rao-Melacini P, Fox KAA, Anand SS, Yusuf S. Association of diet, exercise, and smoking modification with risk of early cardiovascular events after acute coronary syndromes. Circulation. 2010; 121: 750-8.

11. Bassuk SS, Manson JE. Epidemiological evidence for the role of physical activity in reducing risk of type 2 diabetes and cardiovascular disease. J Appl Physiol. 2005; 99: 1193-204.

12. National Cholesterol Education Program (NCEP). Expert panel on detection, evaluation and treatment of high blood cholesterol in adults (Adults Treatment Panel III). Third Report of the National Cholesterol Education program Adult Treatment III. JAMA. 2001; 285: 2486-98.

13. World Health Organization. Definition, diagnosis and classification of diabetes mellitus and its complications: Report of a WHO Consultation. Part 1: Diagnosis and classification of diabetes mellitus. Geneva: World Health Org; 1999.

14. Friedewald WF, Levy RI, Fredrickson DS. Estimation of the concentration of low-density lipoprotein cholesterol in plasma without use of the preparative ultracentrifuge. Clin Chem. 1977; 18: 499-502.

15. Grundy SM, Pasternak R, Greenland P, Smith S, Fuster V. Assessment of cardiovascular risk by use of multiple-riskfactor assessment equations: A statement for healthcare professionals from the American Heart Association and the American College of Cardiology. J Am Coll Cardiol. 1999; 3: 1348-59.

16. Wilson PW, D'Agostino RB, Levy D, Belanger AM, Silbershatz H, Kannel WB. Prediction of coronary heart disease using risk factor categories. Circulation. 1998; 97: 1837-47.

17. Mendivil CO, Sierra ID, Pérez CE. Valoración del riesgo cardiovascular global y prevalencia de dislipidemias según los criterios del NCEP-ATP III en una población adulta de Bogotá Colombia. Clin Invest Arterioscl. 2004; 16: 99-107.

18. Friedman GD, Selby JV, Quesenberry Jr CP, Armstrong MA, Klatsky AL. Precursors of essential hypertension: body weight, alcohol and salt use, and parental history of hypertension. Prev Med. 1988; 17: 387-402. 


\section{Colombia Médica}

19. Lobstein LA. Baur Policies to prevent childhood obesity in the European Union. Eur J Public Health. 2005; 15: 576-9.

20. Tafur LA, Ordoñes G, Millán JC, Varela JM, Rebellón P. Prevalencia de tabaquismo en estudiantes recién ingresados a la Universidad Santiago de Cali. Colomb Med. 2006; 37: 12632.

21. Johnson CC, Nicklas TA, Arbeit ML, Franklin FA, Cresanta JL, Harsha DW, et al. Cardiovascular risk in parents of children with elevated blood pressure. «Heart Smart»: family health promotion. J Clin Hypertens. 1987; 3: 559-66.

22. Reis EC, Kip KE, Marroquin OC, Kiesau M, Hipps Jr L,
Vol. 42 № 1, 2011 (Enero-Marzo)

Peters RE. Screening Children to identify families at increased risk for cardiovascular disease. Pediatrics. 2006; 118: e1789e97.

23. Baena JM, Álvarez B, Piñol P, Martín R, Nicolau M, Altès A. Asociación entre la agrupación (clustering) de factores de riesgo cardiovascular y el riesgo de enfermedad cardiovascular. Rev Esp Salud Publica. 2002; 76: 7-15.

24. Wang NY, Young JH, Meoni LA, Ford DE, Erlinger TP, Klag MJ. Blood pressure change and risk of hypertension associated with parental hypertension. The Johns Hopkins Precursors Study. Arch Intern Med. 2008; 168: 643-8. 